\title{
Causal conditional reasoning and semantic memory retrieval: A test of the semantic memory framework
}

\author{
WIM DE NEYS, WALTER SCHAEKEN, and GÉRY D'YDEWALLE \\ University of Leuven, Leuven, Belgium
}

\begin{abstract}
This study tested and refined a framework that proposes a mechanism for retrieving alternative causes and disabling conditions (Cummins, 1995) during reasoning. Experiment 1 examined the relation between different factors affecting retrieval. The test revealed high correlations between the number of possible alternative causes or disabling conditions and their strength of association and plausibility. Experiment 2 explored the hypothesis that due to a more extended search process, conditional inferences would last longer when many alternative causes or disabling conditions were available. Affirmation of the consequent (AC) and modus ponens (MP) latencies showed the hypothesized pattern. Denial of the antecedent (DA) and modus tollens (MT) inferences did not show latency effects. The experiment also identified an effect of the number of disabling conditions on $\mathrm{AC}$ and DA acceptance. Experiment 3 measured efficiency of disabler retrieval by a limited time, disabler generation task. As predicted, better disabler retrieval was related to lower acceptance of the MP and MT inferences.
\end{abstract}

Conditional reasoning involves making inferences on the basis of an "if-then" relation and is considered one of the cornerstones of human reasoning. Research on conditional reasoning has been trying to identify the factors and processes that affect the performance on these "if-then" inference problems. In a standard conditional inference task, people are asked to assess arguments of the following four kinds:

$\begin{array}{ll}\text { Modus ponens (MP) } & \begin{array}{l}\text { If } \mathrm{p} \text { then } \mathrm{q}, \mathrm{p} \text { there- } \\ \text { fore } \mathrm{q}\end{array} \\ \text { Modus tollens (MT) } & \begin{array}{l}\text { If } \mathrm{p} \text { then } \mathrm{q}, \text { not } \mathrm{q} \\ \text { therefore not } \mathrm{p}\end{array} \\ \text { Denial of the antecedent (DA) } & \begin{array}{l}\text { If } \mathrm{p} \text { then } \mathrm{q}, \text { not } \mathrm{p} \\ \text { therefore not } \mathrm{q}\end{array} \\ \text { Affirmation of the consequent (AC) } & \begin{array}{l}\text { If } \mathrm{p} \text { then } \mathrm{q}, \mathrm{q} \text { there- } \\ \text { fore } \mathrm{p}\end{array}\end{array}$

In standard propositional logic, MP and MT are considered valid inferences and DA and AC are regarded as fallacies.

A growing body of evidence is showing that people's knowledge about the relation between the $\mathrm{p}$ (antecedent) and $\mathrm{q}$ (consequent) part of the conditional has a considerable effect on the reasoning process. In particular, the role

Preparation of the manuscript was supported by grants from the Fund for Scientific Research-Flanders (FWO) and the Belgian Program on Interuniversity Poles of Attraction, Convention No. P4/19. The paper was greatly improved by comments from Evan Heit, Denise Cummins, Mike Oaksford, and Ruth Byrne. Correspondence should be addressed to W. De Neys, Department of Psychology, Tienestraat 102, B-3000, Leuven, Belgium (e-mail: wim.deneys@ psy.kuleuven.ac.be). of knowledge of alternative causes and disabling conditions has attracted interest (see Politzer, in press, for a review).

An alternative cause (alternative) is a possible cause that can produce the effect mentioned in the conditional, whereas a disabling condition (disabler) prevents the effect from occurring despite the presence of the cause. Consider the following conditional:

If the air conditioner is turned on, then you feel cool

Possible alternative causes for this conditional are as follows:

Taking off some clothes, the weather cools, swimming ...

The alternatives make it clear that it is not necessary to turn on the air conditioner in order to feel cool. Other causes are also possible.

Possible disabling conditions are as follows:

Air conditioner is broken, having fever, window open ...

If such disablers are present, turning on the air conditioner will not result in feeling cool. The disablers make it clear that it is not sufficient to turn on the air conditioner in order to feel cool. Additional conditions must be fulfilled.

Rumain, Connell, and Braine (1983) showed that when a possible alternative was explicitly presented to participants, the AC and DA inferences were less endorsed. Byrne (1989) found a similar effect on MP and MT when a possible disabling condition was mentioned. In addition, using familiar relations (e.g., "If an animal has feathers, it is a bird") for which people have ready access to alternatives, Markovits (1986) showed that even without explicit 
presentation, awareness of a possible alternative decreased the number of AC and DA inferences.

Cummins and colleagues (Cummins, 1995; Cummins, Lubart, Alksnis, \& Rist, 1991) have conducted further seminal work on the impact of alternatives and disablers in conditional reasoning. Cummins (1995) and Cummins et al. (1991) directly addressed the role of stored knowledge of alternatives and disablers by examining the effect of the number of available alternatives and disablers. In a pretest they identified causal conditionals (i.e., conditionals that express a causal relation) for which participants generated many or few alternatives and disablers. These conditionals were then adopted for a conditional reasoning task. Results showed that people's acceptance of DA and $\mathrm{AC}$ inferences decreased for conditionals with many possible alternatives. In addition, the number of disabling conditions affected the acceptance of the MP and MT inferences: If there were many conditions that could disable the relation between antecedent and consequent, people tended also to reject these valid inferences. Alternatives and disablers were not explicitly presented, showing that a crucial factor in causal conditional reasoning is the number of alternative causes and disabling conditions people can think of.

Cummins (1995) argued that finding possible alternative causes and disabling conditions affects people's interpretation of the necessity and sufficiency of a cause for bringing about the effect in question. Thompson (1994) showed that the number of disablers and alternatives effect generalized to noncausal conditional relations (e.g., permissions, obligations, and definitions).

The results of Cummins's (1995) experiments imply that during a conditional reasoning task, people search their memory for stored knowledge of alternatives and disablers. Since the outcome of this retrieval process determines which conclusions people are willing to draw, it is of crucial importance for the reasoning community to clarify how the search process is affecting reasoning (JohnsonLaird \& Byrne, 1994; Oaksford \& Chater, 1998).

In a number of studies, Markovits and collaborators have started to specify this search mechanism, which constitutes the core of their general model of conditional reasoning (see Janveau-Brennan \& Markovits, 1999; Markovits, 2000; Markovits, Fleury, Quinn, \& Venet, 1998; Markovits \& Potvin, 2001; Quinn \& Markovits, 1998).

The model states that while making conditional inferences, reasoners will automatically access structures with relevant information in semantic memory. ${ }^{1}$ Such a structure contains semantically or propositionally related elements. In causal conditional reasoning, the structures would consist of possible alternative causes and disabling conditions. Alternatives and disablers would be stored in different structures. According to many influential models of long-term memory (e.g., Anderson, 1983; Gillund $\&$ Shiffrin, 1984), the probability of retrieving at least one element from such a semantic memory structure will depend on the number of elements within the structure. Thus, the probability of retrieving at least one element from the structure storing alternative causes will be higher for conditionals with many possible alternative causes. In the same way, the probability of retrieving a disabling condition will be higher for conditionals with many possible disablers.

The model thus accounts for the effect of number of alternatives and disablers on the underlying reasoning process: The number of possible alternatives and disablers affects successful retrieval of such an element from the corresponding semantic memory structures. When an alternative cause is retrieved, the original antecedent will no longer be perceived as necessary for bringing about the consequent. As a consequence, the DA and AC inferences will be less accepted. Retrieval of a disabling condition will decrease the perceived sufficiency of the original antecedent for bringing about the consequent. This will result in increased rejection of the MP and MT inferences.

We group these ideas under the heading of "semantic memory framework." Although the framework starts specifying a crucial component of the reasoning process, a number of properties are not addressed and remain untested. The present study focuses on this issue. We present three experiments where the characteristics of the semantic search process during conditional reasoning are further tested and explored.

First, we address a neglected issue concerning the relation between different retrieval factors. Remember that one of the framework's central claims is that the probability of successful retrieval is higher for conditionals with many alternatives or disablers. Although it is well established that the probability of retrieval is affected by the number of stored elements, other factors are known to affect the retrieval too. The relation between these factors has to be taken into account in order to validate the claim. A prior concern here is the recently identified impact of "strength of association" on conditional reasoning (see De Neys, Schaeken, \& d'Ydewalle, in press; Quinn \& Markovits, 1998).

Quinn and Markovits (1998) identified the associative strength factor within the semantic memory framework: In the memory structure with possible alternative causes of a conditional, some alternatives will be more strongly associated with the consequent in question than will others. For example, the cause "the dog has fleas" will be more strongly associated with the consequent "a dog scratches constantly" than the cause "the dog has skin disease." Quinn and Markovits showed that in addition to the number of alternative elements in a structure, the relative strength of association facilitated retrieval. In a related study, De Neys et al. (in press) found that the strength of association effect was also present for the disabling conditions.

Participants in Experiment 1 were asked to generate disablers and alternatives for a set of conditionals. As in Cummins's (1995) pretest, we recorded the number of generated alternatives and disablers in order to classify the conditionals in groups with many and few disablers and alternatives. We also recorded how frequently each indi- 
vidual alternative and disabler was generated to measure strength of association (see Quinn \& Markovits, 1998). This allowed us to establish the relation between both retrieval factors.

In addition, plausibility ratings for the individual disablers and alternatives were collected. Since more readily available stored elements will tend to be judged more likely (Kahneman, Slovic, \& Tversky, 1982), this allowed us to take an additional retrieval factor into account.

The impact of the number of stored disablers and alternatives on inference acceptance is well established. In the second experiment we looked for the first time at the impact on the inference latencies. The additional latency data can contribute to a further characterization of the semantic memory framework: Whether or not one has stored many disablers or alternatives will have clear processing consequences. Of primary interest here is the fact that some studies (e.g., Conway \& Engle, 1994) have shown that the time course of a memory search process is affected by the number of elements that are retrieved from a memory structure. It is likely that for conditionals with many disablers or alternatives, more of these elements will be retrieved. Therefore, within the semantic memory framework, one might expect that the time needed for an inference will also be affected by the available number of disablers and alternatives. This was explored in Experiment 2 by recording both acceptance ratings and reaction times for the different inferences in a replication of Cummins (1995). The replication also allowed us to examine the generality of a previously reported (e.g., Liu, Lo, \& Wu, 1996; Markovits \& Potvin, 2001) additional effect of the number of disablers on $\mathrm{AC}$ and DA acceptance.

Finally, in a third experiment we tried to obtain further evidence for the role of the memory search process in conditional reasoning. If the outcome of the search process determines the inferences people draw, we should expect that individual differences in the efficiency of the retrieval process will affect reasoning performance. JanveauBrennan and Markovits (1999) showed that elementary school children's capacity to generate possible alternative conditions was related to their performance on the AC and DA inferences. Here, we tested whether individualdifferences in adult reasoners' capacity to retrieve disabling conditions would affect performance on MP and MT inferences. The semantic memory framework states that the increased rejection of MP and MT results from the successful retrieval of a disabling condition. Since the probability of successful retrieval will be higher for people with a more efficient search process, we predict that the better one is at retrieving disablers from semantic memory, the less one will accept MP and MT.

\section{EXPERIMENT 1 Relation Between Retrieval Factors}

Whether or not the semantic search process retrieves an alternative or disabler depends on more than the number of stored elements. The probability of successful retrieval will also increase with the associative strength or plausibility of the stored elements. In Experiment 1 we examined the relation between different factors affecting the retrieval of stored alternatives and disablers. Participants generated disablers and alternatives for a set of conditionals. On the basis of the number of generated items, conditionals were classified in groups with many and few alternatives or disablers. Associative strength was measured by recording the frequency of generation of the individual alternatives and disablers. After the generation task, participants rated the plausibility of the generated alternatives or disablers.

Within the semantic memory framework, one would expect to see positive relations between the factors of number, associative strength, and plausibility. That is, if conditionals with more disablers also have more strongly associated and plausible disablers, the claim that the probability of successful retrieval is higher for conditionals with many disablers would be validated.

\section{Method}

Participants. Forty students in introductory psychology were enrolled. Half the participants were required to generate possible alternative causes and the other half to generate possible disabling conditions. All participants were native Dutch speakers.

Material. The 16 causal conditionals from Cummins (1995, Experiment $1 \mathrm{~A}$ ) were used for the generation task. Cummins selected these conditionals because they constituted a 2 (few vs. many alternatives) $\times 2$ (few vs. many disablers) manipulation of the factors of number of alternative causes and number of disabling conditions. Another four causal conditionals that seemed to vary in terms of possible alternatives and disablers were taken from the literature. Item format and instructions were similar to those of the generation task in Cummins and Cummins et al. (1991). Thus, the following format was used:

Rule: If the air conditioner is turned on, then you feel cool Fact: You feel cool, but the air conditioner was not turned on

Please write down as many factors as you can that could make this situation possible.

This is an example of the alternative causes generation task. The format of the disabling conditions generation task was similar except that under the heading fact would appear "The air conditioner was turned on, but you don't feel cool." Formats like these were constructed for each of the 20 conditionals; they were typed one to a page in a booklet. The order in which the conditionals appeared in the different booklets was randomized. Task instruction stressed the importance of producing items that were reasonably realistic and different from each other. Participants were instructed that simple variations of the same, simple idea (for the example above, "taking off shirt," "taking off sweater," "taking off coat") would be scored as a single item and should to be avoided.

Procedure. Participants were run in groups of 2 to 6 . The top sheet of the generation task booklet included the written instructions, which were read aloud to the participants. Participants had $1.5 \mathrm{~min}$ to write down their answers for each conditional.

After the generation task, participants received written instructions for the plausibility rating task. They were asked to rate the plausibility of the disablers or alternatives they had generated on an 11-point scale, $(0=$ very implausible $; 10=$ very plausible $)$. Ratings had to be written down in the booklets alongside each generated disabler or alternative. Participants received a practice conditional ("If Bart drinks coffee in the evening, then he doesn't sleep well") with possible disablers or alternatives. Instructions for the disabler rating task made 
clear that we wanted participants to rate how plausible they judged the generated disablers as "explanations" for the nonoccurrence of the specified effects (e.g., "Bart drank coffee in the evening, but he slept well. How plausible is it that this was due to the fact that the coffee was decaffeinated?"). Participants who had generated alternatives were instructed to rate the plausibility of the generated factors as alternative causes for the specified effects (e.g., "Bart did not sleep well. How plausible is it that this was due to the fact that it was too noisy?")

As in Quinn and Markovits (1998) and De Neys et al. (in press), associative strength was measured by recording how frequently an individual alternative or disabler was generated across participants. For example, if 12 of the 20 participants would generate "taking off sweater" as an alternative for "If the air conditioner is turned on, then you feel cool," "taking off sweater" would receive an associative strength of $60 \%$.

The generation protocols were scored by two independent raters in order to identify unrealistic items and items that were variations of a single idea.

\section{Results and Discussion}

Overall, 5.6\% of the generated items were disallowed by the raters. Interrater reliability for the alternatives generation task was .95 and for the disablers generation task was .83 . These figures are in line with the data from the Cummins (1995) generation task.

In general, the mean number of generated alternatives and disablers for the 16 "Cummins" conditionals was also very similar to what was originally reported. Nevertheless, two original conditionals ("If Alvin reads without his glasses, then he gets a headache" and "If the doorbell is pushed, then it will ring") needed to be replaced because the number of generated disablers differed substantially from those in Cummins (1995). Table A1 in the Appendix presents the 16 selected conditionals. The table contains the respective means together with the most frequently generated alternatives and disablers for every conditional.

We were interested in the differences in generation frequency and plausibility ratings of alternatives and disablers for conditionals classified as having many or few of these conditions. Results are summarized in Table 1. Overall, when a conditional had many alternatives or disablers, the disablers (34\% vs. $32 \%$ ) and alternatives (30\% vs. $22 \%$ ) also tended to have a higher association strength. Spearman rank-order correlations confirmed this positive relation between a conditional's number of possible disablers and the disablers' mean association strength $\left[r_{s}=\right.$ $.43, n=16, t(14)=1.77, p<.1]$. The alternatives showed a similar relation $\left[r_{s}=.65, n=16, t(14)=3.23, p<.01\right]$. To provide more detail, we also looked at the number of strongly associated alternatives/disablers in both groups. Three frequency levels (disabler or alternative generated by at least $50 \%, 75 \%$, and $90 \%$ of participants) were used as criterion.

As Table 1 indicates, comparing the number of strongly associated elements supported the global analysis: The group of conditionals with a high number of alternatives also has a higher mean number of strongly associated alternatives (at the 50\%, 75\%, and 90\% levels). The disablers show the same trend at the $50 \%$ and $75 \%$ levels. The high correlations between the number and number of
Table 1

Mean Number and Mean Plausibility of Generated Alternatives/Disablers for Conditionals Classified as Having Many or Few Alternatives/Disablers

\begin{tabular}{lllllll}
\hline & & \multicolumn{2}{c}{ Alternatives } & & \multicolumn{2}{c}{ Disablers } \\
\cline { 3 - 4 } \cline { 7 - 7 } & & Many & Few & & Many & Few \\
\hline Mean Number & & 4.03 & 1.91 & & 4.03 & 2.31 \\
Mean Plausibility & & 6.34 & 5.08 & & 6.29 & 5.21 \\
Mean Number AS & $50 \%$ & 3 & .88 & & 2.88 & 1.75 \\
& $75 \%$ & 1.13 & 0.25 & & 1.5 & 0.75 \\
& $90 \%$ & 0.63 & 0.13 & & 0.5 & 0.5 \\
\hline
\end{tabular}

Note-There are eight conditionals in each group. The last three rows present the mean number of alternatives and disablers generated by at least $50 \%, 75 \%$, and $90 \%$ of the participants. The plausibility rating scale ranged from 0 (very implausible) to 10 (very plausible). AS, associative strength.

strongly associated $(>50 \%)$ alternatives $\left[r_{s}=.82, n=16\right.$, $t(14)=5.82, p<.001]$ and disablers $\left[r_{s}=.73, n=16\right.$, $t(14)=4.01, p<.002]$ supported these findings. ${ }^{2}$

Thus, conditionals with a higher number of possible disablers or alternatives will also have more strongly associated disablers and alternatives. Since both number and strength of association increase the probability of retrieval, these results validate the claim that successful retrieval is more probable for conditionals with many alternatives or disablers.

Table 1 further shows that the generated disablers and alternatives for conditionals classified as having many disablers/alternatives were also rated as more plausible. For the 16 selected conditionals, Spearman rank-order correlations showed a high positive correlation between the number of generated disablers and the mean plausibility of these disablers $\left[r_{s}=.70, n=16, t(14)=4.01\right.$, $p<.002]$. The same trend was observed for the alternatives $\left[r_{s}=.62, n=16, t(14)=2.97, p<.02\right]$. Given the often observed "availability heuristic" (Kahneman et al., 1982), one can assume that the higher plausibility ratings reflect easier retrieval. In this sense, the findings present converging evidence for the strength of association conclusion.

The plausibility rating also gives us an indication of the "quality" of the retrieved disablers and alternatives. Chan and Chua (1994) showed that this "quality" of a presented disabler (i.e., the salience or perceived importance of the disabler in relation to the occurrence of the consequent) affected MP and MT acceptance. This could imply that in addition to the higher retrieval probability, a disabler (or alternative) that is retrieved from a memory structure with many stored elements will have a stronger impact on inference acceptance. Notably, this might be an additional factor that contributes to the effect of the number of alternatives and disablers on conditional reasoning.

\section{EXPERIMENT 2 Inference Study}

First, Experiment 2 explored the effect of the number of stored alternatives and disablers on conditional inference 
latencies. Previous studies have focused solely on the impact on inference acceptance. However, latency data may allow us to further characterize the crucial semantic search process during conditional reasoning.

Experiment 1 showed that for conditionals with many disablers or alternatives, the memory structure storing these elements will typically contain a number of strongly associated elements. Available evidence from memory studies (Conway \& Engle, 1994) suggests that (up to four elements) a semantic search process will take longer when the number of elements that are retrieved from a memory structure increases. When one is making conditional inferences, such a longer search process should result in longer inference times. Thus, availability of many alternatives and disablers might result not only in lower AC/DA and MP/MT inference acceptance but, due to an extended search process, also in longer inference latencies. This expectation was explored by recording both acceptance ratings of the conclusions and the time needed to evaluate them in a replication of Cummins (1995, Experiment 1A).

Second, Experiment 2 allowed us to examine the possible impact of the number of disablers on AC and DA inferences. Liu et al. (1996) and Markovits and Potvin (2001, Experiment 3) observed that AC and DA were more accepted when many disablers were available, although Cummins (1995) did not. At present, the semantic memory framework does not incorporate such an effect. In view of the procedural variations in the cited studies, which might restrict comparability with Cummins's work, we used a large-scale (100 participants) replication to assess the generality of the trend.

It is important to note that in the present study we are interested in the general inference latency pattern. Therefore, in contrast to more traditional reasoning studies, we analyzed latencies in terms of the number (few vs. many) of stored alternatives and disablers independent of the specific acceptance ratings. Furthermore, as in Cummins (1995), a graded rating scale was used to measure inference acceptance. Thus, "acceptance/rejection of an inference" should be interpreted relative to the rating scale (i.e., rejection indicates lower acceptance ratings).

In sum, except for the possible impact of disabling conditions on AC and DA, we expected to replicate Cummins's (1995) findings on the acceptance ratings: MP and MT should be rejected more for conditionals with many disablers than for conditionals with few disablers. AC and DA should be rejected more for conditionals with many alternatives than for conditionals with few alternatives. Given the extended search hypothesis, one would expect longer MP and MT latencies for conditionals with many disablers than for conditionals with few disablers. Likewise, we expected longer AC and DA latencies for conditionals with many alternatives than for conditionals with few alternatives.

\section{Method}

Participants. One hundred and one undergraduate students from the University of Leuven participated as paid volunteers or for par- tial fulfillment of a course requirement. All were native Dutch speakers and none had had training in formal logic.

Materials. The 16 conditionals selected in the generation task (see Table A1) were used. The conditionals yielded a 2 (few/many) $\times 2$ (alternatives/ disablers) design with four items per cell. The 16 conditionals were embedded in the four (MP, DA, MT, and DA) inference types, producing a total of 64 inferences for each participant to evaluate.

The experiment was run on computer. The item format was based on Cummins (1995). Each argument was presented on screen together with a 7-point rating scale and accompanying statements. This resulted in the following format:

Rule: If Jenny turns on the air conditioner, then she feels cool Fact: Jenny turns on the air conditioner

Conclusion: Jenny feels cool

Given this rule and this fact, give your evaluation of the conclusion:

\begin{tabular}{|c|c|c|c|c|c|c|}
\hline \multicolumn{7}{|c|}{5} \\
\hline Very & Sure & Somewhat & I & Somewhat & Sure & Very \\
\hline \multirow[t]{2}{*}{ Sure } & & Sure & I & Sure & & Sure \\
\hline & & & I & & & \\
\hline \multicolumn{3}{|c|}{$\begin{array}{l}\text { That I cannot draw this } \\
\text { conclusion }\end{array}$} & I & & \multicolumn{2}{|c|}{$\begin{array}{r}\text { That I can draw this } \\
\text { conclusion }\end{array}$} \\
\hline
\end{tabular}

Type the number that best reflects your decision about the conclusion:

Each of the 64 arguments was presented in this way. The premises, conclusion, and typed number were always presented in yellow. The remaining text appeared in white on a black background.

Procedure. Participants were run in groups of 2 to 8 . Instructions were presented verbally and on screen, showing an example item that explained the specific task format. Participants were told that the task was to decide whether or not they could accept the conclusions. Care was taken to make sure participants understood the precise nature of the rating scale. Participants used the keypad to type the number reflecting their decision and pressed the Enter key when finished. The next item was presented $750 \mathrm{msec}$ after the Enter key had been pressed. The instructions made clear that there were no time limits, but it was stressed that once participants had made their final decision, they had to press the Enter key immediately. The time between the presentation of the item and pressing the Enter key was recorded together with the acceptance rating. After half of the inferences were evaluated, item presentation stopped until participants decided to continue. Instructions stressed that no other breaks were allowed and participants were expected to work through the items one immediately after another. The 64 items were presented in random order. The experimental session was preceded by one practice trial.

It should be pointed out that, as in Cummins's (1995) study, participants were not explicitly instructed to accept the premises as true and to endorse only conclusions that followed necessarily. Instead, participants could evaluate the conclusions by the criteria they personally judged relevant. With Cummins we assume that this encourages people to reason as they would in everyday circumstances. However, we should note that strictly speaking the task is therefore not a deductive inference task (see Evans, 2000). Endorsing the logically valid (MP and MT) and invalid (AC and DA) inferences should therefore not be considered correct or incorrect reasoning. When we refer to the standard nomenclature, we adopt a nominalist stance toward the use of the terms valid inferences and fallacies.

\section{Results and Discussion}

Each participant evaluated inferences on the basis of four different conditionals within each 2 (number of alternatives) $\times 2$ (number of disablers) $\times 4$ (inference type) cell of the design. The mean of these four observations was calculated. These means were subjected to a $2 \times 2 \times 4$ 

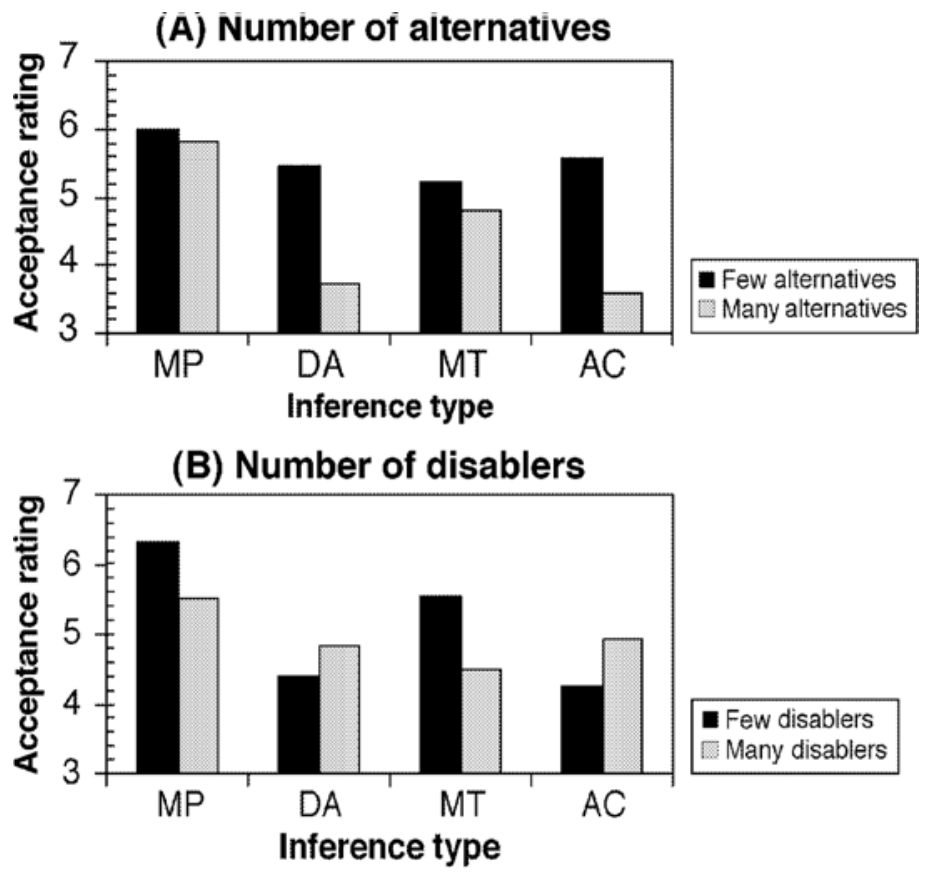

Figure 1. The effect of (A) the number of alternatives and (B) disablers on mean acceptance ratings for the four inference types. The rating scale ranged from 1 (very sure cannot draw this conclusion) to 7 (very sure can draw this conclusion), with 4 representing can't tell.

within-subjects analysis of variance (ANOVA) for acceptance ratings and reaction times.

Effects involving repeated measures with more than two levels were analyzed with multivariate ANOVA tests.

The data from 1 participant were discarded. Mean reaction times differed from the mean reaction times of the sample by more than $3 S D$ on MP, DA, and MT, and $2.5 S D$ on AC.

Acceptance ratings. The main effects of inference type, number of disablers, and number of alternatives were all significant $[$ Rao $R(3,97)=82.19, p<.0001$; $F(1,99)=17.94, M S_{\mathrm{e}}=.89, p<.0001 ; F(1,99)=399.39$, $\left.M S_{\mathrm{e}}=1.17, p<.0001\right]$. As in Cummins (1995), the interactions between inference type and number of disablers $[\operatorname{Rao} R(3,97)=106.41, p<.0001]$ and inference type and number of alternatives [Rao $R(3,97)=96.34, p<.0001]$ were also significant. These interactions are depicted in Figure 1.

Planned contrast tests showed that acceptance of DA $\left[F(1,99)=353.59, M S_{\mathrm{e}}=.85, p<.0001\right]$ and $\mathrm{AC}$ $\left[F(1,99)=383.59, M S_{\mathrm{e}}=1.04, p<.0001\right]$ was significantly lower for conditionals with many alternatives. Further in line with Cummins (1995), the number of disablers affected acceptance of MP $\left[F(1,99)=137.85, M S_{\mathrm{e}}=.48\right.$, $p<.0001]$ and MT $\left[F(1,99)=121.41, M S_{\mathrm{e}}=.94, p<\right.$ $.0001]$, with lower ratings for conditionals with many possible disablers.

These findings replicate Cummins (1995). The present study also identified some additional effects. ${ }^{3}$ First, the number of alternatives affected not only AC and DA but also MP $\left[F(1,99)=7.88, M S_{\mathrm{e}}=.37, p<.01\right]$ and $\mathrm{MT}$
$\left[F(1,99)=29.8, M S_{\mathrm{e}}=.6, p<.0001\right]$ acceptance: For conditionals with many alternatives, slightly lower MP and MT ratings were obtained. Nevertheless, there was still an interaction between inference type and number of alternatives. As is clear from Figure 1A, the MP and MT effects were smaller than the impact of alternative retrieval on AC and DA.

The MP and MT findings can be explained if one takes into account that in our set of conditionals there was a positive correlation $\left(r_{s}=.37\right.$, n.s.) between a conditional's number of possible alternatives and disablers (see Thompson, 2000, Appendix E, for a similar observation). Therefore, conditionals with many alternatives will also tend to have a slightly higher number of disablers than conditionals with few alternatives. Consequently, since retrieving disablers will be somewhat more probable for conditionals with many alternatives, the lower MP and MT acceptance is not surprising.

Second, the findings of Liu et al. (1996) and Markovits and Potvin (2001, Experiment 3 ) were replicated: In addition to the impact on MP and MT, the number of disablers also affected DA and AC acceptance. Both DA $[F(1,99)=$ $\left.38.16, M S_{\mathrm{e}}=.47, p<.0001\right]$ and $\mathrm{AC}[F(1,99)=74,13$, $\left.M S_{\mathrm{e}}=.58, p<.0001\right]$ were accepted more when many disablers were available. This effect cannot be explained by the correlation between the number of alternatives and disablers since this would result in a trend in the opposite direction.

A possible explanation points toward an interplay between the disablers and alternatives search processes. Markovits and Potvin (2001) observed that disabler re- 
trieval can occur during a search for alternative causes. This suggests that retrieval of alternatives and disablers is not occurring in complete isolation. Note that at present the specific relation between both search processes is not specified in the semantic memory framework. We can assume that retrieving stored memory elements is resource demanding. A plausible hypothesis would be that retrieving (many) disablers puts a load on the cognitive system. This load would then burden the search for alternative causes. Thus, retrieval of alternatives would be less efficient for conditionals with many disablers, which would result in a lower retrieval probability and thus higher $\mathrm{AC}$ and DA acceptance. Consistent with this hypothesis, the effect of the number of disablers was mediated by the available number of alternatives on both $\mathrm{AC}[F(1,99)=$ $\left.6.56, M S_{\mathrm{e}}=.34, p<.015\right]$ and DA $[F(1,99)=6.04$, $\left.M S_{\mathrm{e}}=.5, p<.02\right]$ : Disabler retrieval affecting $\mathrm{AC}$ and DA was less pronounced for the conditionals that had few alternatives. Indeed, when few alternatives are available, successful retrieval is not likely anyway. Thus, an eventual burden of the search process should not be expected to have a major impact here.

Though interesting, the explanation is not unproblematic. For example, given that alternative retrieval did not increase MP and MT acceptance, one needs to explain why retrieval of disablers would burden retrieval of alternatives although the reverse does not occur. Such a pattern suggests that retrieving disablers somehow has priority over retrieving alternatives. It is clear that this issue demands further research. Meanwhile, in the light of recent demonstrations of the interplay between disabler and alternative retrieval processes (Markovits \& Potvin, 2001), the overload mechanism should not be discarded.
Reaction times. In order to eliminate biased measures, a trimming procedure was applied to the reaction times before they were subjected to analysis. For every inference type, any latency that was more than $3 S D$ above a person's mean reaction time for that inference type was discarded. This procedure affected less than $1 \%$ of all observations.

The MANOVA revealed a significant main effect of inference type $[\operatorname{Rao} R(3,97)=43.03, p<.0001]$. As for the acceptance ratings, we also observed significant interactions between inference type and number of alternatives $[\operatorname{Rao} R(3,97)=4.82, p<.004]$ and inference type and number of disablers [ $\operatorname{Rao} R(3,97)=2.7, p<.05]$. These interactions are depicted in Figure 2.

Planned contrasts tests indicated that the $\mathrm{AC}[F(1,99)=$ 5.47, $\left.M S_{\mathrm{e}}=7.52, p<.025\right]$ inference took more time $(641 \mathrm{msec})$ for conditionals with many alternatives (Figure 2A). Likewise, the $\mathrm{MP}\left[F(1,99)=11.52, M S_{\mathrm{e}}=5.27\right.$, $p<.001$ ] inferences required more time $(776 \mathrm{sec})$ for the conditionals with many disablers (Figure 2B).

These findings show that the higher number of stored alternatives and disablers results not only in lower AC and MP acceptance, but also in increased inference latencies. This corroborates the hypothesized extended semantic search process for conditionals with many alternatives or disablers: When many (strongly associated) alternatives and disablers are available, retrieval of additional alternatives and disablers will result in longer inference latencies.

Although the number of available disablers and alternatives affected MT and DA acceptance, no effects were observed on the latencies. Thus, DA and MT latency data suggest there is no extended search process for these inferences. The findings can be reconciled if one takes into
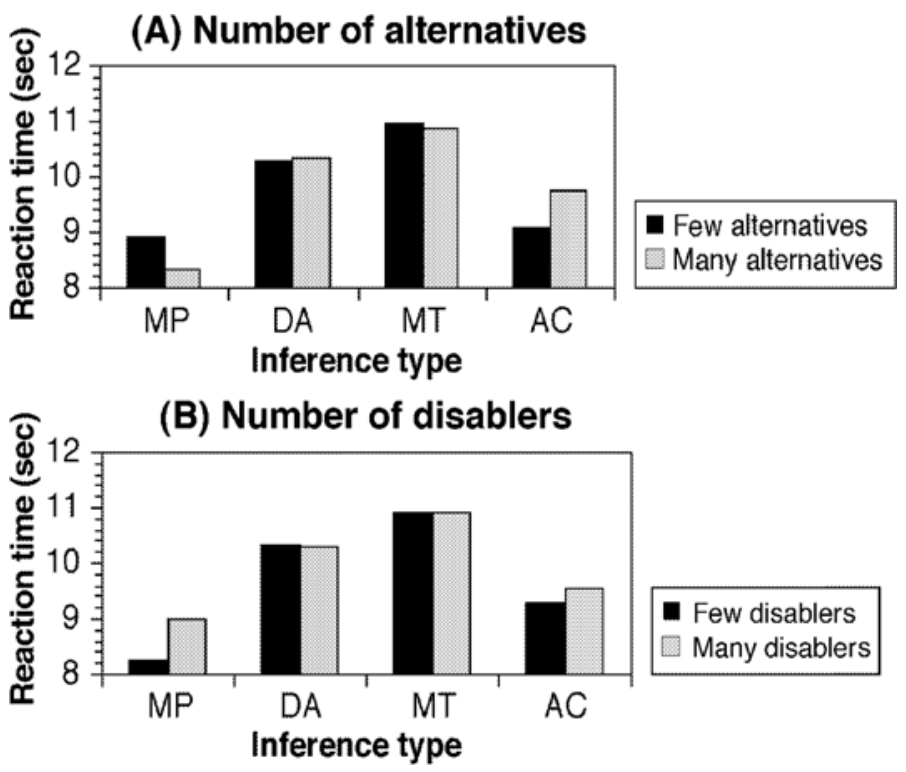

Figure 2. The effect of (A) the number of alternatives and (B) disablers on mean reaction times for the four inference types. 
account that the semantic search process during conditional reasoning is possibly affected by inference complexity. DA and MT inferences are more complex than AC and MP inferences. DA and MT, the so-called denial inferences, involve negations, and reasoning theories typically state that these demand more cognitive (working memory) resources (Braine \& O'Brien, 1998; JohnsonLaird \& Byrne, 1993; Oaksford, Chater, \& Larkin, 2000). Rosen and Engle (1997) have shown that semantic memory retrieval is affected by working memory load. Therefore, the increased complexity may affect the semantic search process. Due to the higher load, the search would be less extensive. The additional need to process negations would thus override the extended search for DA and MT inferences.

In general, this implies that for DA and MT based on conditionals with many alternatives/disablers, fewer of these elements will be retrieved than for MP and AC. Therefore, one might expect a less pronounced effect of the number of alternatives and disablers on DA and MT acceptance ratings. However, one has to consider that when the reasoning system is already burdened, retrieval of even a single alternative might cause a cognitive overload. Such an overload can result in increased inference rejection (e.g., Toms, Morris, \& Ward, 1993). Therefore, even with a less extensive search process, availability of many alternatives/disablers can still result in considerable decreased MT and DA acceptance. Consistent with this claim, planned contrast test showed that the number of disablers had a similar impact on MP and MT acceptance ratings. Likewise, AC and DA acceptance was not differentially affected by the number of available alternatives.

As Figure 2A indicates, MP inferences also lasted longer $(595 \mathrm{msec})$ when few alternatives were available $\left[F(1,99)=11.9, M S_{\mathrm{e}}=2.97, p<.001\right]$. This effect of alternatives on MP reaction times is puzzling. The direction of the effect, with many alternative conditionals having shorter reaction times, was the opposite of the other latency effects. At present, we have no clear-cut explanation for this finding.

\section{EXPERIMENT 3 \\ Individual Differences in Disabler Retrieval Capacity}

In Experiment 3 we tried to obtain further evidence for the role of the semantic search process during conditional reasoning. We tested whether individual differences in adult reasoners' capacity to retrieve disabling conditions affected performance on MP and MT inferences. The semantic memory framework states that the increased rejection of MP and MT results from the successful retrieval of a disabling condition. Since the probability of successful retrieval will be higher for people with a more efficient search process, we would expect that the better one is at retrieving disablers from semantic memory, the less MP and MT should be accepted.

We do not predict an effect on the inference latencies. Reasoners with a more efficient retrieval process can be expected to be faster at retrieving disablers. Although more efficient retrievers will probably retrieve more disablers, the faster running search process will compensate the extra time needed for the additional retrieval.

Retrieval efficiency was measured by looking at the number of generated disablers in a generation task that was presented to 40 participants after the inference task of Experiment 2 . The generation task used four new conditionals and four conditionalsalready presented in the inference task. The new conditionals were included because generation for the old conditionals may be biased by familiarity. On the other hand, retrieval of disablers for adult participants may be highly specialized and conditional specific. In this latter case, generation of disablers for the new conditionals would not be informative for the retrieval efficiency for conditionals in the inference task. Comparing the results for the old and new conditionals allows us to sidestep this possible complication.

\section{Method}

Participants. Forty participants that participated in Experiment 2 took part in the present experiment.

Materials. Disabler retrieval capacity was measured by requesting participants to generate possible disablers for eight conditionals. Half the conditionals had already been presented to participants in the inference study (= old conditionals), and the other half were different (= new conditionals). Half the old and new conditionals had been classified in previous work as possessing many disabling conditions, and the other half had only few possible disabling conditions. Item format and task instructions were similar to those for the generation task in Experiment 1. The conditionals appeared in the same order in all booklets. The old conditionals were presented after the new ones.

Procedure. The retrieval measure was presented after all participants of a group had finished the inference study. Generation time was limited to $30 \mathrm{sec}$ for the new conditionals, as in Janveau-Brennan and Markovits (1999). To account for faster reading times (and thus more retrieval time) due to previous presentation, generation time was limited to $28 \mathrm{sec}$ for the old conditionals. Participants had to write down their answers. Instructions stressed the importance of writing down only the general core of the retrieved disablers, in order not to lose time because of the writing itself. The generated disablers were scored according to the list of accepted disablers as provided by the raters in our previous studies.

\section{Results and Discussion}

We disallowed $5.66 \%$ of the generated disablers in the retrieval measure, mainly because they expressed variations of the same idea according to the previous classifications. The Spearman rank-order correlation between the generated number of disablers for the new and old conditionals was rather high $\left[r_{s}=.65, n=40, t(38)=\right.$ $5.30, p<.001]$.

Acceptance ratings. We first analyzed the relation between participants' mean MP, DA, MT, and AC acceptance rating in Experiment 1 and the total number of disablers they generated for the eight conditionals in the retrieval task. Spearman rank-order correlations indicated that both MP $\left[r_{s}=-.35, n=40, t(38)=-2.33\right.$, $p<.03]$ and MT $\left[r_{s}=-.40, n=40, t(38)=-2.67, p<\right.$ .02] showed the expected significant negative relation: The more disablers people could retrieve in a limited time 
period, the less they accepted MP and MT. Acceptance of DA $\left(r_{s}=.09\right)$ and $\mathrm{AC}\left(r_{s}=.13\right)$ was not significantly related to disabler retrieval capacity.

The same analysis was run with the number of generated disablers for the new and old conditionals as separate indexes of retrieval capacity. Both indexes pointed to the same conclusions: There were significant or marginally significant negative correlations with MP [old, $r_{s}=$ $-.31, n=40, t(38)=-1.97, p<.06$, new, $r_{s}=-.31$, $n=40, t(38)=-1.98, p<.06]$ and MT acceptance ratings [old, $r_{s}=-.41, n=40, t(38)=-2.75, p<.01$, new, $\left.r_{s}=-.31, n=40, t(38)=-.98, p<.06\right]$, but there was no effect on DA and AC. Together with the high correlation between the generated number of disablers for the old and new conditionals, this indicates that both indexes are measuring the same capacity. Therefore, in the remaining analyses we used only the total number of generated disablers as the index of retrieval efficiency.

To provide a more global picture of the observed effects, we classified participants in three groups according to the total number of generated disablers in the retrieval task. Participants giving 17 or fewer disablers were classified as low $(n=10, M=14.2)$, participants giving 23 or more disablers were classified as high $(n=12, M=$ 24.8 ), while the remaining participants were classified as intermediate $(n=18, M=20)$. For each of the four inference types, we performed an ANOVA on the acceptance ratings with retrieval capacity as a between-subjects factor and number of alternatives and disablers as a withinsubjects factor. This resulted in a 3 (retrieval) $\times 2$ (many/ few alternatives) $\times 2$ (many/few disablers) design. Because the pattern of results for the number of alternatives and disablers variables repeated what had been found in the inference study, we only report results relating to the retrieval capacity factor.

Acceptance of both MP $\left[F(1,37)=4.19, M S_{\mathrm{e}}=2.64\right.$, $p<.03]$ and MT $\left[F(1,37)=4.40, M S_{\mathrm{e}}=4.94, p<.02\right]$ was affected by the retrieval factor $[F(1,37)=4.19$, $\left.M S_{\mathrm{e}}=2.64, p<.03\right]$. These effects are depicted in Figure 3. Newman-Keuls tests showed that participants with low (6.29) and intermediate (6.23) capacity to retrieve disablers from semantic memory accepted MP significantly more than the high-capacity group (5.44). A similar effect was observed for MT, with the low (5.51) and intermediate (5.44) groups giving higher ratings than the participants in the high group (4.33). The differences between the low and intermediate groups were not significant. Both for MP and MT, interactions of the retrieval and number of disabler and alternatives factors were not significant, which indicates that the retrieval factor has a similar effect on conditionals with few and many disablers.

As noted, Janveau-Brennan and Markovits (1999) found that children's capacity to retrieve alternatives was related to acceptance of DA and AC. The more alternatives children could retrieve, the less they accepted both inferences. This corroborates the present findings. However, in addition Janveau-Brennan and Markovits observed that an efficient retrieval of alternatives resulted in lower MP acceptance. Although there was no effect

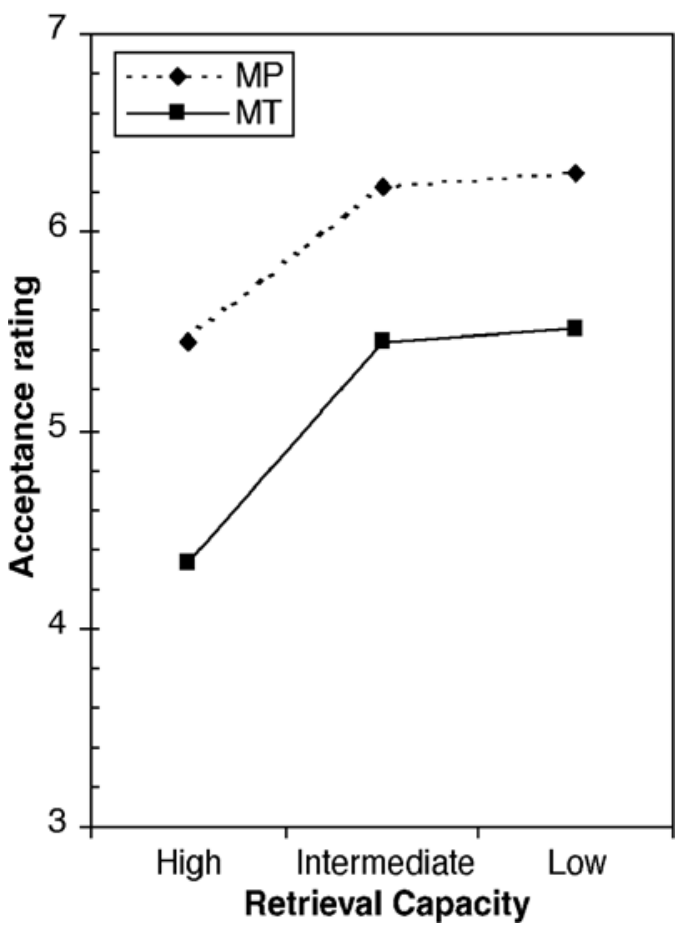

Figure 3. The effect of disabler retrieval capacity on MP and MT acceptance ratings. Retrieval capacity is measured by the number of generated disablers (low, high, or intermediate) in the generation task.

on MT, they interpreted this as evidence for a general retrieval capacity. In the present study, DA and AC acceptance ratings were not affected by participants' capacity to retrieve disablers from semantic memory. This suggests that for adult reasoners, retrieval capacity for alternatives and disablers is not related.

Reaction times. Spearman rank-order correlations between participants' mean MP, DA, MT, and AC latencies in the inference task and the total number of generated disablers for the eight conditionals in the retrieval task were calculated. Although the DA $\left(r_{s}=-.25\right)$, AC $\left(r_{s}=-.20\right)$, and MT $\left(r_{s}=-.16\right)$ correlations showed a negative trend, none of the correlations were significant (not even at the .1 level). When the analysis was run with number of generated disablers for the new and old conditionals as separate indexes of retrieval capacity, the same, nonsignificant, pattern was observed.

As expected, these findings indicate that good disabler retrievers do "more in the same time." Although they will retrieve more disablers, which is time-consuming, the retrieval will be faster than for people with less efficient retrieval capacities. Hence, the inference time is not affected.

\section{GENERAL DISCUSSION}

The results of the present study support and refine the semantic memory framework of conditional reasoning. This framework explains the effect of the number of pos- 
sible disablers and alternatives of a conditional and integrates it with the underlying reasoning process. It states that the possible alternatives and disablers of a conditional are stored in semantic memory structures and that reasoners access these structures when presented with a conditional inference problem. The framework further assumes that the number and strength of association of the elements in the memory structures affect successful retrieval. Retrieval of a disabler will decrease the perceived sufficiency of the original antecedent for bringing about the consequent. This results in an increased rejection of the MP and MT inferences. When an alternative cause is retrieved, the original antecedent will no longer be perceived as necessary for bringing about the consequent. As a consequence, the DA and AC inferences are less accepted.

We started the study with an examination of the relation between different factors affecting retrieval of alternatives and disablers. We observed high correlations between the different factors: Conditionals with many elements in the semantic memory structures had a higher number of strongly associated elements, and the elements were also rated as more plausible. This supported the framework's central claim that successful retrieval is more likely when many alternatives or disablers are available.

The second experiment explored the impact of the number of available alternatives and disablers on conditional inference latencies. It was hypothesized that due to a more extended search process, inferences would last longer when many alternatives or disablers could be retrieved. Consistent with this claim, AC took more time for conditionals with many alternatives, whereas MP latencies increased when many disabling conditions were available. For MT and DA inferences there was no evidence for an extended search process. We hypothesized that the additional need to process negations for MT and DA overrides the retrieval of additional alternatives or disablers. In addition to Cummins's (1995) findings, Experiment 2 also identified an impact of the number of available disablers on AC and DA acceptance: When many disablers were available, AC and DA were accepted more. We argued that this finding suggests an interplay between the alternative and disabler search processes.

In Experiment 3 the role of the semantic search process during conditional reasoning was further established. As expected, individual differences in the efficiency of the disabler retrieval process affected inference acceptance. The better people were at retrieving disablers, the less MP and MT were accepted.

This study supports the semantic memory framework, but it is important to note that possible alternative accounts might be suggested. Especially with respect to the latency data, such a possible alternative explanation is provided by the mental models theory (Johnson-Laird, 1983; JohnsonLaird, Byrne, \& Schaeken, 1992). We should note that unlike Cummins (1995), Markovits and collaborators (e.g., see Markovits, 2000; Markovits et al., 1998) have incorporated the semantic memory framework into this general reasoning theory.
Mental models theory could explain the increased MP and $\mathrm{AC}$ latencies as the result of an additional mental representation process. The theory will state that retrieval of an alternative or disabler alters the mental representation of the conditional that is used as the basis for inferences: After successful retrieval, the initial representation of the conditional will be extended with an additional model (Byrne, Espino, \& Santamaria, 1999). The additional model would represent the possibility that occurrence of the antecedent is not linked with occurrence of the consequent (for a disabler) or the fact that the consequent can be linked with different alternatives (for an alternative). In Byrne et al. these extra models constitute what the authors referred to as the "recursive" and "conditional" interpretation of a conditional. Now, the additional model construction is known to be time-consuming (see Barrouillet, Grosset, \& Lecas, 2000). Since the additional representation will be constructed only when retrieval of an alternative or disabler is successful, this can partially explain the longer inference latencies. Thus, the possible contribution of such a representational process to the MP and AC latency findings should not be discounted at this point.

The present study also points toward some important issues that are currently not addressed in the semantic memory framework. A prior concern is that the framework needs to establish the precise relation between the different processes taking part in conditional reasoning. At present the framework assumes, for example, that the processes of representing the conditional, processing negations, and searching for stored alternatives and disablers are occurring in complete isolation. We believe the findings of Experiment 2 suggest this is not the case. Rather, the different processes would "compete for limited resources." The crucial role of working memory in both conditional reasoning (e.g., Barrouillet \& Lecas, 1999; Meiser, Klauer, \& Naumer, 2001; Toms et al., 1993) and semantic memory retrieval (e.g., Rosen \& Engle, 1997) has been established. Thus, it is likely that the processes that are crucial in the semantic memory framework are all burdening the limited working memory resources. Therefore, it would not be surprising that processing of negations affects the extent of the search process or that disabler retrieval affects the search for alternatives. Furthermore, the fact that some processes can have priority over others (e.g., disabler retrieval over alternative retrieval) might help to explain some of the puzzling findings in the present study.

However, we acknowledge that our findings should be interpreted with some caution. Experiment 2 is the first experiment where the effect of alternative and disabler retrieval on inference latencies has been examined. Establishing the specific relation between the retrieval processes and eliminating possible alternative suggestions will demand more detailed research. Nevertheless, the obtained results legitimate the further development of the framework. The present study has thus established the semantic memory framework as a viable starting point for unraveling the complicated relationship between inference processes and memory retrieval processes. 


\section{REFERENCES}

Anderson, J. R. (1983). The architecture of cognition. Cambridge, MA: Harvard University Press.

Barrouillet, P., Grosset, N., \& Lecas, J. F. (2000). Conditional reasoning by mental models: Chronometric and developmental evidence. Cognition, 75, 237-266.

Barrouillet, P., \& LECAS, J. F. (1999). Mental models in conditional reasoning and working memory. Thinking \& Reasoning, 5, 289-302.

Braine, M. D. S., \& O'Brien, D. P. (Eds.) (1998). Mental logic. Mahwah, NJ: Erlbaum.

BY RNE, R. M. J. (1989). Suppressing valid inferences with conditionals. Cognition, 31, 61-83.

Byrne, R. M. J., Espino, O., \& Santamaria,C. (1999). Counterexamples and the suppression of inferences. Journal of Memory \& Language, 40, 347-373.

Chan, D., \& ChuA, F. (1994). Suppression of valid inferences: Syntactic views, mental models, and relative salience. Cognition, 53, 217-238.

Conway, A. R. A., \& ENGLE, R. W. (1994). Working memory and retrieval: A resource-dependent inhibition model. Journal of Experimental Psychology: General, 123, 354-373.

Cummins, D. D. (1995). Naive theories and causal deduction. Memory \& Cognition, 23, 646-658.

Cummins, D. D., Lubart, T., Alksnis, O., \& Rist, R. (1991). Conditional reasoning and causation. Memory \& Cognition, 19, 274-282.

De Neys, W., Schaeken, W., \& D'Ydewalle, G. (in press). Causal conditional reasoning and strength of association: The disabling condition case. European Journal of Cognitive Psychology.

EvANS, J. ST. B. T. (2000). What could and could not be a strategy in reasoning. In W. Schaeken, G. De Vooght, A. Vandierendonck, \& G. d'Ydewalle (Eds.), Deductive reasoning and strategies (pp. 241-265). Mahwah, NJ: Erlbaum.

Gillund, G., \& Shiffrin, R. M. (1984). A retrieval model for both recognition and recall. Psychological Review, 91, 1-67.

Janveau-Brennan, G., \& Markovits, H. (1999). The development of reasoning with causal conditionals. Developmental Psychology, 35, 904-911.

JoHnSON-LAIRD, P. N. (1983). Mental models: Towards a cognitive science of language, inference, and consciousness. Cambridge, MA: Cambridge University Press.

Johnson-Laird, P. N., \& BYrne, R. M. J. (1993). Précis of deduction. Behavioral \& Brain Sciences, 16, 323-380.

Johnson-Laird, P. N., \& Byrne, R. M. J. (1994). Models, necessity, and the search for counterexamples. Behavioral \& Brain Sciences, 17, 775-778.

Johnson-Laird, P. N., Byrne, R. M. J., \& Schaeken, W. (1992). Propositional reasoning by model. Psychological Review, 99, 418-439.

Kahneman, D., Slovic, P., \& Tversky, A. (1982). Judgement under uncertainty: Heuristics and biases. Cambridge, MA: Cambridge University Press.

LiU, I., Lo, K., \& WU, J. (1996). A probabilistic interpretation of "if-then." Quarterly Journal of Experimental Psychology, 49A, 828-844.

MARKovITS, H. (1986). Familiarity effects in conditional reasoning. Journal of Educational Psychology, 78, 492-494.

Markovirs, H. (2000). A mental model analysis of young children's conditional reasoning with meaningful premises. Thinking \& Reasoning, 6, 335-347.
Markovits, H, Fleury, M., Quinn, S., \& Venet, M. (1998). The development of conditional reasoning and the structure of semantic memory. Child Development, 69, 742-755.

Markovits, H., \& Potvin, F. (2001). Suppression of valid inferences and knowledge structures: The curious effect of producing alternative antecedents on reasoning with causal conditionals. Memory \& Cognition, 29, 736-744.

Meiser, T., Klauer, K. C., \& Naumer, B. (2001). Propositional reasoning and working memory: The role of prior training and pragmatic content. Acta Psychologica, 106, 303-327.

OAKSFord, M., \& ChATER, N. (1998). Rationality in an uncertain world: Essays on the cognitive science of human reasoning. Hove, UK: Psychology Press.

OAKsford, M., Chater, N., \& Larkin, J. (2000). Probabilities and polarity biases in conditional inference. Journal of Experimental Psychology: Learning, Memory, \& Cognition, 26, 883-899.

Politzer, G. (in press). Premise interpretation in conditional reasoning. In D. Hardman \& L. Macchi (Eds.), Reasoning and decision making. New York: Wiley.

QuinN, S., \& MARKovits, H. (1998). Conditional reasoning, causality, and the structure of semantic memory: Strength of association as a predictive factor for content effects. Cognition, 68, B93-B101.

Rosen, V. M., \& ENGLE, R. W. (1997). The role of working memory capacity in retrieval. Journal of Experimental Psychology: General, 126, 211-227.

Rumain, B., Connell, J., \& Braine, M. D. S. (1983). Conversational comprehension processes are responsible for reasoning fallacies in children as well as adults. Developmental Psychology, 19, 471-481.

THOMPSON, V. A. (1994). Interpretational factors in conditional reasoning. Memory \& Cognition, 22, 742-758.

Thompson, V. A. (2000). The task-specific nature of domain-general reasoning. Cognition, 76, 209-268.

Toms, M., Morris, N., \& Ward, D. (1993). Working memory and conditional reasoning. Quarterly Journal of Experimental Psychology, 46A, 679-699.

Tulving, E. (1983). Elements of episodic memory. Oxford: Clarendon.

\section{NOTES}

1. As the introductory examples make clear, alternatives and disablers are typical instances of a person's general knowledge about the world, usually stored in semantic memory (Tulving, 1983). Of course, this does not exclude the possibility that some alternatives or disablers, tied to a specific personal experience, might be retrieved from episodic memory. 2. It should be noted that Quinn and Markovits (1998) measured strength of association in a generation task that allowed only $30 \mathrm{sec}$ generation time, whereas the present study allowed $1.5 \mathrm{~min}$ (as in Cummins, 1995). It could be argued that this longer generation time confounded the strength of association measure. However, for the retrieval efficiency measure in Experiment 3 we used a disabler generation task with $30 \mathrm{sec}$ generation time. This allowed us to compare the frequency data for six conditionals with $30 \mathrm{sec}$ and $1.5 \mathrm{~min}$ generation time. The crucial relative ranking of the disablers was hardly affected: Spearman rank-order correlation reached $.84[t(82)=13.71, p<.000]$.

3 . We refer to additional effects because these were not significant in Cummins (1995). However, there were trends in the same direction (see Figure 3, p. 653). 
APPENDIX

Table A1

Mean Number and Mean Plausibility (P) of Generated Alternatives (Alt) and Disablers (Dis) for the 16 Conditionals Adopted for the Inference Study

\begin{tabular}{|c|c|c|c|c|c|c|}
\hline Conditional & Alt & $\mathrm{P}$ & $50 \%$ alternatives & Dis & $\mathrm{P}$ & $50 \%$ Disablers \\
\hline \multicolumn{7}{|c|}{ Many Alternatives, Many Disablers } \\
\hline $\begin{array}{l}\text { 1. If fertilizer is put on } \\
\text { plants, then they grow } \\
\text { quickly }\end{array}$ & 3.7 & 6.84 & $\begin{array}{l}\text { Well watered }(75 \%) \\
\text { Lots of sunlight }(70 \%) \\
\text { Fertile soil }(55 \%) \\
\text { Naturally fast } \\
\quad \text { growers }(50 \%)\end{array}$ & 4.5 & 6.52 & $\begin{array}{l}\text { No water }(75 \%) \\
\text { Plants dying }(65 \%) \\
\text { No sunlight }(55 \%) \\
\text { Too much/little }(55 \%) \\
\quad \text { applied } \\
\text { Wrong type }(55 \%)\end{array}$ \\
\hline $\begin{array}{l}\text { 2. If the brake is depressed, } \\
\text { then the car slows down }\end{array}$ & 4.1 & 6.02 & $\begin{array}{l}\text { Uphill }(70 \%) \\
\text { Foot off accelerator }(60 \%) \\
\text { Out of gas }(55 \%) \\
\text { Collision }(55 \%)\end{array}$ & 3.5 & 6.21 & Brake broken $(85 \%)$ \\
\hline $\begin{array}{l}\text { 3. If John studies hard, } \\
\text { then he does well } \\
\text { on the test }\end{array}$ & 4.4 & 5.47 & $\begin{array}{l}\text { Cribbing }(90 \%) \\
\text { Easy test }(70 \%) \\
\text { Lucky }(60 \%)\end{array}$ & 4.9 & 6.26 & $\begin{array}{l}\text { Test too hard }(75 \%) \\
\text { Not concentrated }(60 \%) \\
\text { Low IQ }(50 \%)\end{array}$ \\
\hline $\begin{array}{l}\text { 4. If Jenny turns on the air } \\
\text { conditioner, then she } \\
\text { feels cool }\end{array}$ & 4.6 & 6.16 & $\begin{array}{l}\text { Took off clothes }(75 \%) \\
\text { Open window }(60 \%)\end{array}$ & 4.2 & 5.70 & $\begin{array}{l}\text { Air conditioner broken }(95 \%) \\
\text { Fever }(50 \%)\end{array}$ \\
\hline \multicolumn{7}{|c|}{ Many Alternatives, Few Disablers } \\
\hline $\begin{array}{l}\text { 5. If Bart's food goes down } \\
\text { the wrong way, then } \\
\text { he has to cough }\end{array}$ & 3.6 & 6.92 & $\begin{array}{l}\text { Catch a cold }(100 \%) \\
\text { Attract attention }(80 \%)\end{array}$ & 2.1 & 5.07 & $\begin{array}{r}\text { Choked not hard } \\
\text { enough }(80 \%)\end{array}$ \\
\hline $\begin{array}{l}\text { 6. If Marry jumps into the } \\
\text { swimming pool, then she } \\
\text { gets wet }\end{array}$ & 4.4 & 6.46 & $\begin{array}{l}\text { Rains }(100 \%) \\
\text { Shower }(60 \%)\end{array}$ & 2.5 & 4.93 & $\begin{array}{l}\text { Pool empty (100\%) } \\
\text { Wearing dry-suit (95\%) }\end{array}$ \\
\hline $\begin{array}{l}\text { 7. If the apples are ripe, } \\
\text { then they fall from the tree }\end{array}$ & 3.4 & 6.16 & $\begin{array}{l}\text { Storm }(95 \%) \\
\text { Tree shaken by agent } \\
\quad(55 \%) \\
\text { Dropped by picker }(55 \%)\end{array}$ & 2.1 & 5.23 & Picked $(65 \%)$ \\
\hline $\begin{array}{l}\text { 8. If water is poured on the } \\
\text { campfire, then the fire }\end{array}$ & 4 & 6.57 & $\begin{array}{l}\text { Died out }(95 \%) \\
\text { Smothered with } \\
\text { blanket/sand }(80 \%) \\
\text { Rain }(60 \%) \\
\text { Wind blew out }(55 \%)\end{array}$ & 2.5 & 5.96 & $\begin{array}{l}\text { Too little water }(90 \%) \\
\text { Very large fire }(65 \%)\end{array}$ \\
\hline \multicolumn{7}{|c|}{ Few Alternatives, Many Disablers } \\
\hline $\begin{array}{l}\text { 9. If the trigger is pulled, } \\
\text { then the gun fires }\end{array}$ & 1.7 & 4.24 & Faulty design (55\%) & 3 & 6.40 & $\begin{array}{l}\text { No bullets }(100 \%) \\
\text { Gun broken }(75 \%)\end{array}$ \\
\hline $\begin{array}{l}\text { 10. If the correct switch is } \\
\text { flipped, then the porch } \\
\text { light goes on }\end{array}$ & 1.9 & 5.68 & Faulty wiring $(50 \%)$ & 3.9 & 7.21 & $\begin{array}{l}\text { No power }(100 \%) \\
\text { Missing or broken } \\
\text { bulb }(95 \%) \\
\text { Switch broken }(75 \%)\end{array}$ \\
\hline $\begin{array}{l}\text { 11. If the ignition key is } \\
\text { turned, then the car starts }\end{array}$ & 1.8 & 5.28 & Hot wired $(75 \%)$ & 4.2 & 6.19 & $\begin{array}{l}\text { Engine/car broken }(75 \%) \\
\text { Wrong key }(50 \%) \\
\text { No fuel }(50 \%)\end{array}$ \\
\hline $\begin{array}{l}\text { 12. If the match is struck, } \\
\text { then it lights }\end{array}$ & 1.8 & 5.85 & $\begin{array}{l}\text { Lit with other } \\
\quad \text { fire }(100 \%)\end{array}$ & 4 & 5.83 & $\begin{array}{l}\text { Match wet }(80 \%) \\
\text { Not struck hard enough } \\
\quad(75 \%) \\
\text { Worn matchbox pad }(60 \%) \\
\text { Used match }(50 \%)\end{array}$ \\
\hline \multicolumn{7}{|l|}{ Few Alternatives, Few Disablers } \\
\hline $\begin{array}{l}\text { 13. If Joe cuts his finger, } \\
\text { then it bleeds }\end{array}$ & 3.1 & 5.52 & $\begin{array}{l}\text { Scraped/scratched (60\%) } \\
\text { Removed scab }(50 \%)\end{array}$ & 2.7 & 5.76 & $\begin{array}{l}\text { Cut not deep enough } \\
\quad(100 \%) \\
\text { Knife blunt }(65 \%) \\
\text { Cut in nail/callous }(65 \%)\end{array}$ \\
\hline $\begin{array}{l}\text { 14. If Larry grasps the glass } \\
\text { with his bare hands, then } \\
\text { his fingerprints are on it }\end{array}$ & 1.6 & 3.97 & $\begin{array}{l}\text { [Still on from earlier } \\
\quad \text { grasp }(35 \%)]^{*}\end{array}$ & 1.9 & 4.67 & Hands not greasy $(50 \%)$ \\
\hline $\begin{array}{l}\text { 15. If the gong is struck, } \\
\text { then it sounds }\end{array}$ & 2.3 & 4.51 & $\begin{array}{l}\text { Gong fell/bumped } \\
\quad(55 \%)\end{array}$ & 2.7 & 4.53 & $\begin{array}{l}\text { Struck too lightly }(70 \%) \\
\text { Padded/gripped }(70 \%) \\
\text { Struck with light material } \\
\quad(55 \%)\end{array}$ \\
\hline $\begin{array}{l}\text { 16. If water is heated to } \\
100^{\circ} \mathrm{C} \text {, then it boils }\end{array}$ & 1.1 & 5.5 & $\begin{array}{l}\text { [Still warm from } \\
\quad \text { earlier heating }(20 \%)]^{*}\end{array}$ & 2 & 5.49 & No pure water $(75 \%)$ \\
\hline
\end{tabular}

Note-The relative frequency of generation for conditions that were mentioned by at least $50 \%$ of participants is presented in order of frequency. The plausibility rating scale ranged from 0 (very implausible) to 10 (very plausible). *Most frequently generated alternative. 


\section{APPENDIX (Continued)}

Table A2

Characteristics of the Additional Conditionals Not Selected in Experiment 1

\begin{tabular}{|c|c|c|c|c|c|c|}
\hline Conditional & Alt & $\mathrm{P}$ & $50 \%$ alternatives & Dis & $\mathrm{P}$ & $50 \%$ Disablers \\
\hline $\begin{array}{l}\text { 1. If Alvin reads without } \\
\text { his glasses, then he gets } \\
\text { a headache }\end{array}$ & 4.5 & 6.29 & $\begin{array}{l}\text { Bonked head }(75 \%) \\
\text { Fever }(65 \%) \\
\text { Hangover }(55 \%)\end{array}$ & 3.5 & 6.36 & $\begin{array}{l}\text { Took aspirin }(85 \%) \\
\text { Wore contacts }(70 \%) \\
\text { Didn't read long }(70 \%) \\
\text { Large print book }(50 \%)\end{array}$ \\
\hline $\begin{array}{l}\text { 2. If the doorbell is pushed, } \\
\text { then it will ring }\end{array}$ & 1.8 & 4.37 & Malfunction (65\%) & 3.15 & 6.14 & $\begin{array}{l}\text { Bell broken }(90 \%) \\
\text { Not pushed hard } \\
\text { enough }(75 \%) \\
\text { No power }(60 \%)\end{array}$ \\
\hline $\begin{array}{l}\text { 3. If Jan consumes alcohol, } \\
\text { then he gets drunk }\end{array}$ & 2 & 4.67 & $\begin{array}{l}\text { [Spinning around } \\
\qquad(40 \%)]^{*}\end{array}$ & 3.15 & 7 & $\begin{array}{l}\text { Consumes only a } \\
\quad \text { little }(85 \%) \\
\text { Ate a lot }(75 \%) \\
\text { Low percent alcohol }(50 \%)\end{array}$ \\
\hline $\begin{array}{l}\text { 4. If Steve goes in for sports, } \\
\text { then he loses weight }\end{array}$ & 4 & 6.46 & $\begin{array}{l}\text { Ate less }(75 \%) \\
\text { Sick }(75 \%) \\
\text { Stress }(70 \%) \\
\text { Ate healthy } \\
\quad \text { food }(65 \%)\end{array}$ & 3.2 & 6.58 & $\begin{array}{l}\text { Low intensity/frequency } \\
\quad(100 \%) \\
\text { Bad diet }(90 \%) \\
\text { Playing chess/pool }(65 \%)\end{array}$ \\
\hline
\end{tabular}

Note-Alt, generated alternative; P, plausibility; Dis, disabler. *Most frequently generated alternative.

(Manuscript received January 9, 2001;

revision accepted for publication April 29, 2002.) 